\title{
Instructors’ Ideas about Problem Solving - Setting Goals
}

\author{
Charles Henderson*, Kenneth Heller*, Patricia Heller*, Vince H. Kuo*, Edit Yerushalmi* ${ }^{\xi}$ \\ *Physics Education Research Group, University of Minnesota, Minneapolis, MN \\ ${ }^{\xi}$ Weizmann Institute, Rehovot, Israel
}

\begin{abstract}
This paper presents preliminary hypotheses about the relationship between faculty goals for the introductory calculus-based physics course and their beliefs about student learning of problem solving. All faculty have problem solving as a major goal for their course. There appears to be however, an instructional paradox. When discussing how students learn to solve problems in their own courses, faculty indicate that reflective-practice skills are a necessary prerequisite, and that average students enter the course with these skills. When discussing general problem solving skills, however, faculty seem to believe that similar reflective-practice skills cannot be learned in an introductory physics course, and should be a long-term goal of university education.
\end{abstract}

\section{Introduction}

This is the third paper in a series of three describing an interview study designed to formulate hypotheses about how physics faculty view the teaching and learning of problem solving in the introductory calculus-based course. The first paper $^{1}$ focused on grading and describes both the interview and the selection of the faculty sample. The second paper $^{2}$ presents hypotheses about faculty beliefs of how students learn problem solving. This paper describes the course goals for all 30 faculty interviewed. It also presents hypotheses about: (1) the relationship between faculty goals and their beliefs about how students learn for six research university faculty; and (2) which students these faculty expect will meet their goals.

\section{Goals Survey}

Prior to being interviewed, faculty members were asked to complete a written "Goals Survey". This survey listed 16 possible goals for the introductory calculus-based course. Faculty were asked to rate the importance of each goal for their course on a five point scale from "not at all important"

\begin{tabular}{|c|c|c|c|c|c|}
\hline & Goal & $\begin{array}{c}\text { RU } \\
\text { Avg } \\
(\mathrm{N}=6)\end{array}$ & $\begin{array}{c}\text { CC } \\
\text { Avg } \\
(\mathrm{N}=7)\end{array}$ & $\begin{array}{c}\text { PC } \\
\text { Avg } \\
(\mathrm{N}=9)\end{array}$ & $\begin{array}{c}\text { SU } \\
\text { Avg } \\
(\mathrm{N}=8)\end{array}$ \\
\hline \multirow{3}{*}{ 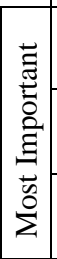 } & $\begin{array}{l}\text { Know the basic principles behind all physics (e.g. forces, } \\
\text { conservation of energy,...). }\end{array}$ & 4.5 & 4.7 & 4.7 & 5.0 \\
\hline & $\begin{array}{l}\text { Solve problems using general quantitative problem solving skills } \\
\text { within the context of physics. }\end{array}$ & 4.5 & 3.9 & 4.6 & 4.6 \\
\hline & $\begin{array}{l}\text { Solve problems using general qualitative logical reasoning within } \\
\text { the context of physics. }\end{array}$ & 4.5 & 4.1 & 4.4 & 4.4 \\
\hline \multirow{3}{*}{ 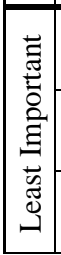 } & $\begin{array}{l}\text { Understand and appreciate "modern physics" (e.g. solid state, } \\
\text { quantum optics, cosmology, quantum mechanics, nuclei, particles,...). }\end{array}$ & 2.5 & 2.0 & 2.2 & 2.8 \\
\hline & $\begin{array}{l}\text { Understand and appreciate the historical development and } \\
\text { intellectual organization of physics. }\end{array}$ & 2.3 & 2.1 & 2.9 & 2.9 \\
\hline & $\begin{array}{l}\text { Program computers to solve problems within the context of } \\
\text { physics. }\end{array}$ & 2.0 & 2.0 & 2.3 & 1.6 \\
\hline
\end{tabular}

Table 1: Average faculty rating of three most important and three least important goals from a list of 16 possible goals for the introductory calculus-based physics course. The rating is on a 5-point scale from $1=$ not at all important to $5=$ very important. (RU=research university, $\mathrm{CC}=$ community college, $\mathrm{PC}=$ private college, $\mathrm{SU}=$ state university) 
to "very important", and to mark the two goals they thought were most important. The results of this survey are shown in Table 1 . There is a strong agreement among the different groups of faculty about which goals are most important and which goals are least important. For the two most important goals, "know the basic principles behind all physics" and "solve problems using general quantitative problem solving skills" were picked more often than any of the other goals.

\section{Goals and Learning Beliefs}

The remainder of this paper will focus on hypotheses about faculty goals generated by an in-depth analysis of the interviews of the six research university (RU) faculty. For these faculty, course goals appear consistent with their beliefs about how students learn (see the second paper in this series ${ }^{2}$ ). They believe that physics principles (e.g. conservation of energy) and specific knowledge (e.g. how to use the right hand rule) can be explicitly told to students - that if they do a good job of explaining these things to the students then the students will learn them. On the other hand, these faculty believe that other aspects of problem solving (e.g. using knowledge, being systematic, evaluating your answer) can best be learned through "reflective practice" by individual students.

There are, however, some difficulties in this seemingly simple and coherent system. Faculty believe that (1) most students do not engage in the necessary reflective practice; and (2) it takes a long time to be able to learn to be reflective in problem solving. Most faculty expect few students to have incorporated all of the problem solving skills by the end of the introductory physics course.

\section{Interview Data - Meeting Problem Solving Goals}

Throughout each interview, the interviewer wrote a separate note card for each statement that the faculty indicated might be important for a student solving a physics problem. During the final part of the interview, the faculty were asked to categorize these cards into groups of their choosing. Table 2 shows the most common types of problem solving skill categories of the faculty, along with an indication of the percentage of students they thought had attained these skills by the end of their course. Five of the six faculty (all except faculty \#5) indicated that they were satisfied with this result. When asked, faculty said that they did not believe that all of the problem solving skills were reasonable to expect students to obtain in a one-year course. Furthermore, not all students were capable or motivated enough to learn problem solving skills.

\section{SIGNS OF MATURITY}

The problem solving skills category of "signs of maturity" is seen as the most difficult for students to achieve. Depending on the instructor, they think that between $25 \%$ and $75 \%$ of the students leave their course without acquiring these mature problem solving skills. They see their course as contributing to a student's growth in this area, but don't expect to see the results until several years into the future. They also indicate that they make no efforts to teach mature problem solving nor do they attempt to evaluate it.

For 4 of the faculty, being a mature problem solver includes skills like "realizing the final result is too large", or "playing around to see what approaches might be valuable". Faculty \#4 does not disconnect maturity from the physics concepts. He talks about it in terms of having "good insight" or "having a grasp of the qualitative features of a problem”. Faculty \#5 saw problem solving as being fairly well-defined in what he described as a "medical-school method". 


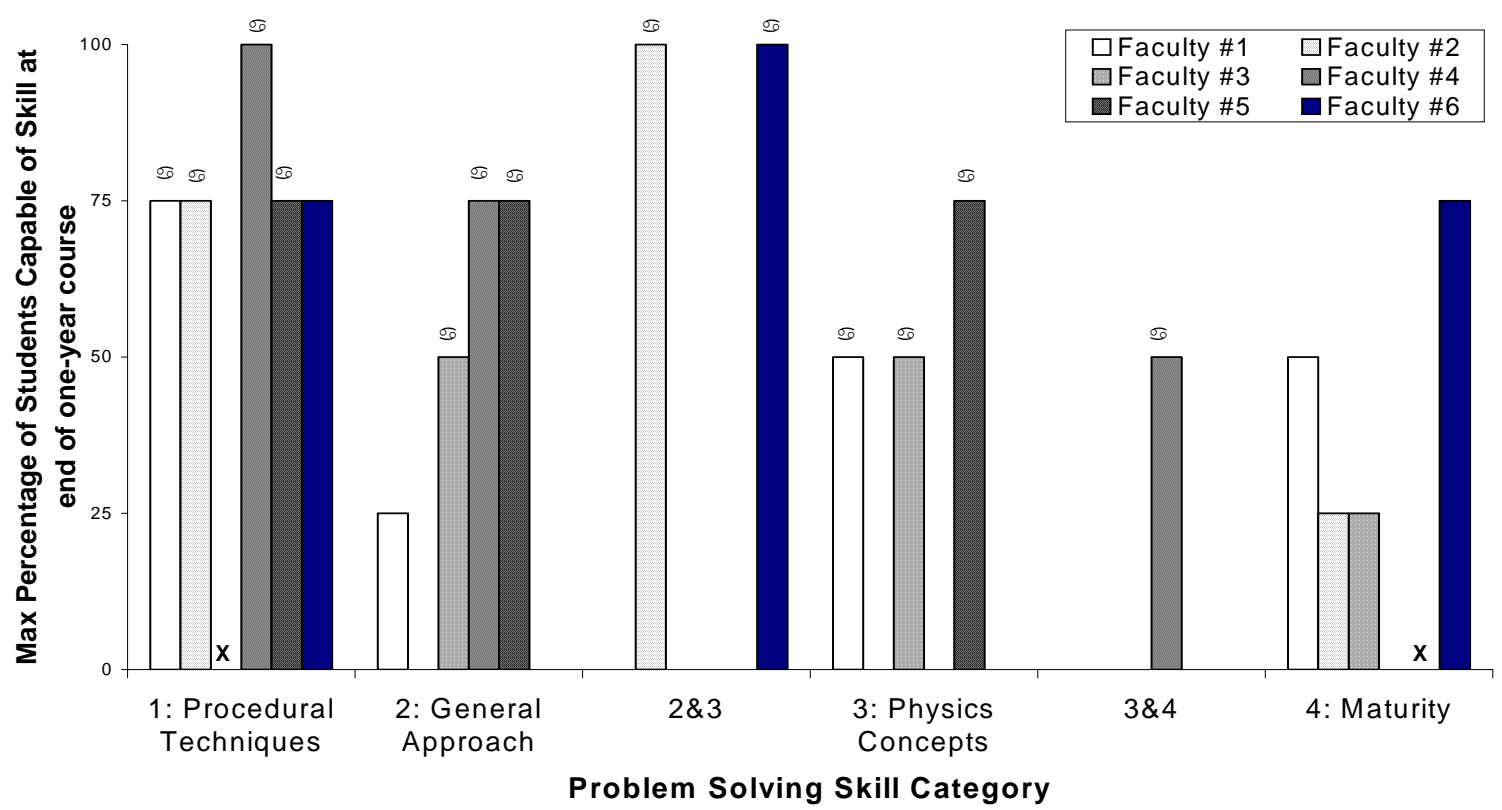

Table 2: RU faculty categorizations of problem solving skills. Caterogy \#1: Procedural Skills (e.g. "Draw vector diagrams”), \#2: Decide on General Approach (e.g. "Develop a strategy to arrange principles”), \#3: Understand Physics Concepts and How to Use Them (e.g. "Know that tension in string in a circular path does no work"), \#4: Signs of Maturity (e.g. "Recognize when something is missing"). An "X" in place of a column means that the instructor did not make such a category. " $2 \& 3$ " and " $3 \& 4$ " indicate that the instructor did not distinguish between two categories that other instructors separated. A "+" above the column means that the instructor indicated that the category is something that is reasonable to expect students to be able to do after one year of physics.

Physics students would approach a problem like a doctor would approach a patient making decisions based on a "tree structure" that will eventually lead you to the correct diagnosis, or problem solution.

These signs of maturity are things that educators often include under the category of metacognitive skills (Bereiter and Scardamalie $^{3}$ discuss metacognitive skills, as well as the relationship between learning and problem solving), although none of the faculty referred to them as such. It is important to note that there appears to be a large degree of similarity between the skills students need to be mature problem solvers and the skills students need to engage in reflective practice (see the second paper in this series ${ }^{2}$ ). It is not clear whether the faculty interviewed made this connection.

\section{WHICH STUDENTS CAN LEARN?}

All instructors said that there were students who were "hopeless" and "just couldn't learn". This percentage was estimated to be between $10-25 \%$ of their class. On the other end of this "innate qualities" scale, instructors believe that there are about 1-2\% of their students who don't have to work hard to do well in the class. For the remainder of the students, whether they learn depends on how much time they put into doing reflective practice.

However, the faculty believe that most students do not engage in reflective practice. Logically there are three possible reasons why a student might not engage in reflective practice: The student might (1) not know how; (2) know how, but not believe that it is necessary; or (3) know how and know that it is necessary, but choose not to do it. 
Because of the similarity between their descriptions of reflective practice and problem solving skills that are difficult for students to learn (signs of maturity), one would expect them to choose the first reason during this part of the interview. Nevertheless, in all 6 interviews with the RU faculty the $1^{\text {st }}$ possibility was only mentioned once. The difficulty of students not engaging in reflective practice was discussed as if faculty believed that the $2^{\text {nd }}$ or $3^{\text {rd }}$ possibility was correct. Even then, they rarely mentioned encouraging students to engage in reflective practice.

\section{Discussion}

The purpose of looking in-depth at the six RU faculty is to develop hypotheses. The next stage of this research will be to attempt to test these hypotheses using the remaining interviews and, later, with a larger sample of faculty. This paper has explored several issues relating to faculty goals. Based on these issues the following hypotheses can be made.

- All faculty have very similar course goals: Students will learn the basic physics principles and develop problem solving skills within the context of physics.

- There are two seemingly contradictory reasons that faculty are satisfied with their course outcomes: (1) Faculty believe that some problem solving skills - primarily the reflective signs of maturity - cannot be learned in a single year-long course. (2) Faculty believe that many students are capable of reflective practice but do not put in the time necessary to learn problem solving. They see this as the students' freedom of choice and do not attempt to change the situation.

- Faculty make no attempt to teach the skills within signs of maturity even though these skills are necessary for solving problems. (For example, an instructor could break down the skills in signs of maturity and set goals for where students should be by they end of the introductory course.)
- Faculty do not offer any explicit explanations of how a student can learn through reflective practice, only that it is necessary. This suggests that faculty may not fully understand the process.

From this preliminary analysis of faculty goals, it seems that the RU faculty we interviewed know many of the prerequisites (most importantly, reflective practice) for learning problem solving skills. Faculty beliefs about student abilities, however, appear to be context-dependent. When discussing problem-solving skills, faculty indicate that students are not capable of signs of maturity. When discussing skills needed to learn problem solving, however, they say that students are capable of the very similar reflective practice. Attempting to better understand these apparently conflicting beliefs will be an important goal of further analysis based on the remaining 24 interviews.

Knowing about faculty goals and expectations can allow curriculum developers to better match curricular designs to the beliefs of faculty. This, however, requires that faculty have consistent beliefs about student learning, which does not appear to be the case. When faculty hold inconsistent (conflicting) beliefs about student learning, any successful curricular development effort will require a component of professional development.

\footnotetext{
${ }^{1}$ Kuo, V. H., Heller, K., Heller, P., Henderson, C., \& Yerushalmi, E. Instructors' Ideas about Problem Solving - Grading. Proceedings of the Physics Education Research Conference, Rochester, NY, July, 2001.

${ }^{2}$ Heller, P., Heller, K., Henderson, C., Kuo, V. H., \& Yerushalmi, E. Instructors' Beliefs and Values about Learning Problem Solving. Proceedings of the Physics Education Research Conference, Rochester, NY, July, 2001.

${ }^{3}$ Bereiter, C., \& Scardamalie, M. Cognition and Curriculum in Philip W. Jackson (ed.) Handbook of Research on Curriculum, MacMillan, New York, 1992.
} 